Peer-Reviewed Article

OJED

ISSN: 2162-3104 Print/ ISSN: 2166-3750 Online

Volume 9, Issue 2 (2019), pp. 432-459

doi: $10.32674 /$ jis.v9i2.607

(C) Journal of International Students

https://ojed.org/jis/

\title{
Online Social Networking and Transnational- Competence Development Among International Students from Japan
}

\author{
Phyllis Bo-Yuen Ngai \\ The University of Montana-Missoula, USA
}

\begin{abstract}
Social media has become the window to the world near and far for international students. Apart from socializing and connecting with friends, what educational outcomes can be attributed to social networking sites (SNSs)? This study examines the possibility that intercultural interactions on SNS can serve as a means of developing the transnational competence required for effective participation in an interconnected world. In this exploratory study, Japanese students studying in the United States participated in a mixed-method study involving (1) a structured questionnaire about their perceived empowerment benefits of frequenting global SNSs and (2) semi-structured interviews about the nature of these intercultural interactions on SNSs. The implications of Facebook use for transnational-competence development are explored.
\end{abstract}

Keywords: intercultural communication, internationalization, social media, transnational competence

\section{INTRODUCTION}

Online social networking has become a global phenomenon. Social media has infiltrated the daily lives of university students regardless of cultural and 
linguistic background. The findings from a survey conducted in 21 nations by the Pew Research Center's Global Attitudes Project indicated that people under age 30 and those with a college education are more likely than others to engage in social networking (Pew Research Center, 2015, 2018). Among the plethora of social-networking possibilities, Facebook has become by far the most popular site in the world. According to a January 4, 2013, Washington Post report, "Facebook now dominates 127 of the 137 countries" (Khazan, 2013, p.1) with over 2.23 billion active monthly users (Facebook, 2018). Although the creation of social-networking sites is mainly for fun (Madge, Meek, Wellens, \& Hooley, 2009; Prescott, Wilson, $\&$ Beckett, 2013), this study aimed to find out if frequent use of this new medium can enhance learning in terms of interpersonal-skill development.

Social-networking sites (SNSs) transcend all kinds of barriers that could hinder interpersonal contacts, including geographical, social, psychological, linguistic, and cultural distances and differences. For instance, Facebook has challenged the conventional wisdom that there are six degrees of separation between everyone on the planet. Using its "friend graph" to calculate the degrees separating its billions of members, Facebook found that the average interpersonal distance is as few as 3.57 people (Hunt, 2016). Thus, this technological development presents unprecedented possibilities for international communication. Such online fora can serve as "thriving sites of intercultural communicative exchange" (Pfister \& Soliz, 2011, p. 247) and can provide the space for cross-boundary dialogue that otherwise would not have occurred (Alvarez Valencia \& Benavides, 2018; Witteborn, 2011).

For international students, SNSs offer a novel place to develop and maintain relationships and to share interests (Kotowski \& Dos Santos, 2010). There is growing evidence that cross-cultural use of Facebook can provide benefits both for people settling in a culturally unfamiliar country and for the native people of that country (Jiang \& de Bruijn, 2014; Tian, 2016). To tap opportunities presented by this compelling and irreversible communication trend, more and more educators use social media to facilitate knowledge sharing, to support social interactions, and to create a sense of community in the educational setting (see for example, Alvarez Valencia \& Benavides, 2018; Avram, 2014; Hung \& Yuen, 2010; Prescott et al., 2013; Sharma, Joshi, \& Sharma, 2016). Of particular interest in this article are the potential outcomes of intercultural interactions frequently engaged in by international students on Facebook.

Specifically, this study examines the possibility that intercultural interactions over SNSs such as Facebook can serve as a means of 
developing the transnational competence required for effective participation in an interconnected world (Koehn \& Rosenau, 2010). For international students who strive to become competent in English-speaking international contexts, but lack opportunities to polish and test out their English communication skills, fruitful intercultural interactions on SNSs can be helpful. An exploratory study with a group of Japanese students studying in the United States sheds some light on skill development via SNSs. Of particular interest are the implications of study findings regarding Facebook use for transnational-competence development.

\section{LITERATURE REVIEW}

\section{Intercultural Learning on Social Networking Sites}

McEwan and Sobre-Denton (2011) described social media as the virtual boundary-spanning third spaces where "a plethora of cultural influences can come together" to create a "multinational, multicultural... hybridized global citizenry..." (p. 256). Further, SNSs "help constitute communities of discourse united by shared interest..." (Pfister \& Soliz, 2011, p. 247). On the other hand, there is evidence of considerable variation in the form and expression of online interactions (Jiang, de Bruijn, \& De Angeli, 2009; Qiu, Lin, \& Leung, 2013). For instance, a study comparing persuasion styles used on Mixi (a Japanese-dominated SNS) with those used on Facebook indicates that Mixi's approach to persuasion is subtle and the influence tactics are less direct and require more time to achieve results in comparison with those found on Facebook (Fogg \& Iizawa, 2008). Another study discovered that "American young women are more prone to public expressions of connection with peer group members via their Facebook photographs" while "Japanese young women are much more likely to communicate closeness via Mixi diaries" (Barker \& Ota, 2011, p. 39).

The studies included in this literature review indicated that Facebook is the most widely used SNS among international students studying in the United States, although other SNSs might be employed as well. Given the widespread Facebook usage among young people of diverse linguistic and cultural backgrounds, studies that investigate the effects of exposure to Facebook-communication style on nonnative English-speaking, non-U.S. student users are likely to be rewarding. According to a review of research on Facebook as an educational environment, Facebook has "powerful effects on language teaching and learning" and it "could be used to facilitate English learning" among nonnative English-speaking students (Aydin, 
2012, p. 1099; see also K. Lee \& Ranta, 2014). In some cases, the users learn to speak like and think like Americans (see Placencia \& Lower, 2013). In other cases, users are able to develop the skills to code switch, to synthesize multiple perspectives, and to learn from diversity in order to bridge differences creatively (see Zuckerman, 2013). For instance, Mao and Qian (2015) found that Facebook communication among Chinese professionals in Western countries reflected Chinese traditional culture in many ways, while at the same time the Chinese expatriates regarded Facebook as a useful acculturation tool to learn about the host cultures.

In Rewire, Zuckerman (2013) argued that the international flow of information and ideas on the Internet will not magically turn us into transnationally competent people. If we want to maximize the benefits of social media, we need to take responsibility for using its connective tools for educational purposes. If users consciously or subconsciously approach online social networking as a means of learning from interactions with people of different cultural backgrounds, educators can gain by learning about the kinds of competencies that SNSs can and cannot help to enhance. This study specifically examines the possibility that interactions on SNSs such as Facebook can serve as a means of developing the transnational competence required for effective participation in the interconnected world.

\section{Transnational Competence as a Learning Outcome}

For exploring the potential positive impacts of SNS usage on skill development, the transnational-competence framework developed by Koehn and Rosenau (2010) provides a useful yardstick. On the basis of crossdisciplinary meta-analysis, Koehn and Rosenau presented a comprehensive description of the skills required for college graduates in the 21 st century. The term transnational competence (TC) first appeared in the report Towards Transnational Competence: Rethinking International Education (a U.S./Japan case study), prepared by the Task Force for Transnational Competence with support from the U.S./Japan Foundation in 1997. Task Force members foresaw that education in the new millennium would need to place greater emphasis on TC (see also Song, 2016). Koehn and Rosenau, political scientists specializing in international relations, considered the treatment of TC in the Institute of International Education report timely, but narrow and thin. 


\begin{tabular}{|c|c|}
\hline Competence & Definition \\
\hline $\begin{array}{l}\text { Analytic } \\
\text { competence }\end{array}$ & $\begin{array}{l}\text { - Ability to achieve a reasonably complete } \\
\text { understanding of the central beliefs, values, } \\
\text { practices, \& paradoxes of counterpart } \\
\text { culture(s) \& society(ies), including political } \\
\text { \& ethnic awareness. } \\
\text { Ability to link conditions in new settings to } \\
\text { one's own circumstances \& vice versa. } \\
\text { - Ability to discern risks and benefits and to } \\
\text { assess complex alternative sociotechnical } \\
\text { paths. } \\
\text { Ability to discern effective transboundary } \\
\text { interaction strategies and to learn from past } \\
\text { successes and failures. }\end{array}$ \\
\hline $\begin{array}{l}\text { Functional } \\
\text { (project/task) } \\
\text { competence }\end{array}$ & $\begin{array}{l}\text { - Ability to relate to counterpart(s) and to } \\
\text { develop and maintain positive interpersonal } \\
\text { relationships. } \\
\text { - Ability to apply/adapt procedural insights, } \\
\text { empathy, and imagination in transboundary } \\
\text { interactions. } \\
\text { - Flexible ability to employ extensive \& } \\
\text { complex range of accommodative } \\
\text { organizational strategies \& interaction paths. } \\
\text { Ability to overcome problems/conflicts and } \\
\text { accomplish goals when dealing with } \\
\text { transnational and transboundary challenges } \\
\text { and globalization/localization pressures. } \\
\text { Ability to build and activate professional } \\
\text { and societal resources that mitigate } \\
\text { socioeconomic inequities, power } \\
\text { differentials, exclusionary policies, and } \\
\text { other institutionalized constraints. }\end{array}$ \\
\hline $\begin{array}{l}\text { Communicative } \\
\text { competence }\end{array}$ & $\begin{array}{l}\text { - Proficiency in \& use of counterparts' } \\
\text { spoken/written language. } \\
\text { - Skill in interpretation \& in using an } \\
\text { interpreter. }\end{array}$ \\
\hline
\end{tabular}


Emotional

competence

Creative/imaginative competence
- Proficiency in \& relaxed use of interculturally appropriate nonverbal cues and codes.

- Ability to listen to and discern different messages.

- Ability to engage in meaningful transboundary dialogues; to facilitate mutual self-disclosure.

- Ability to avoid \& resolve communication misunderstandings across diverse communication styles.

- Motivation and ability to open oneself up continuously to divergent cultural influences experiences.

- Ability to assume genuine interest in, and to maintain respect for, different values, traditions, experiences, feelings, \& challenges.

- Ability to read emotional messages conveyed by people with vastly different backgrounds.

- Ability to manage multiple identities.

- Sense of transboundary efficacy.

- Ability to foresee and exploit the synergistic potential of diverse group perspectives in collective problem solving.

- Collaborative ability to articulate novel and shared transboundary syntheses.

- Ability to envision viable mutually acceptable alternatives.

- Ability to tap into diverse cultural sources for inspiration.

Note. "Transnational Competence: Empowering Professional Curriculum for Horizon-Rising Challenges" by Peter H. Koehn and James N. Rosenau (2010, pp. 8-9).

They subsequently published their independently constructed comprehensive TC framework based on a thorough cross-disciplinary 
review of the literature in a book subtitled Empowering Professional Curricula for Horizon-Rising Challenges. They "approach transnational encounters as micro level interpersonal interactions that occur in a social/power context and are shaped by macro level forces (global, regional, crossborder, national, and local)" (Koehn \& Rosenau, 2010, p. 8). Their TC framework includes five sets of capacities: analytic, emotional, creative/imaginative, communicative, and functional competences (see Table 1).

Application of Allport's (1954) intergroup-contact theory helps further inform our exploration of possible links between intercultural interactions and TC development. Meta-analysis of studies about intergroup-contact theory provides evidence that intergroup or intercultural contacts increase empathy for and knowledge about "the other" and, therefore, serves to reduce prejudice. A study of the physiological manifestation of the intergroup-contact theory showed that increased contacts with stereotyped others, including people of different racial backgrounds, can reduce feelings of threat toward those groups (Blascovich, Mendes, Hunter, Lickel, \& Kowai-Bell, 2001). These generalized effects of intergroup contacts can be viewed as indicators of emotional competence under the TC framework. Some of the studies testing Allport's hypothesis also indicated that having outgroup friends, such as college peers of different cultural backgrounds, can result in positive effects beyond that of simply diminishing prejudice. Intergroup or intercultural friendship can induce greater empathy with outgroup members as well as reduce anxiety during interactions with people who are of different backgrounds (Pettigrew, 2008). Both empathy and a sense of transboundary efficacy are key elements of emotional competence under the TC framework. Moreover, increased contact with cultural others is likely to improve self-assessment of skills and abilities, particularly the ability to communicate effectively (Blascovich et al., 2001). The efficacy resulting from all of these attainments is a form of functional competence in the TC framework.

While the potential benefits of intergroup contact emerge from constructive face-to-face encounters that serve to reduce intergroup hostility, fear, or other negative emotions springing from uncertainty, online contacts could offer similar potential benefits. Lebedko (2014) found that the digital generation highly value the help received from their virtual societies and the wide horizons opened to them on SNSs. AmichaiHamburger and McKenna (2006) speculated that online contacts are as beneficial as face-to-face contacts (if not more so) because the Internet allows participants to overcome some of the challenges posed by face-to- 
face communication. Thus, the Internet can function as a contact environment that meets the conditional requirements for transformative learning suggested in intergroup-contact theory (Amichai-Hamburger \& McKenna, 2006).

Another aspect of emotional-competence development involves developing a fluent identity. Friendship-formation strategies and communication skills used on SNSs are "associated with the perceived availability of social, personal, and instrumental resources" (McEwan \& Guerrero, 2010, p. 445). One study discovered, for example, that Asian international students maintained a transcultural space in the online world in which they sort through the cultural norms and values of their home countries and the host country and "carry out an uninhibited cultural navigation amid the distinct yet connected zones" on SNS (Kim, Yun, \& Yoon, 2009, p. 152). Social networking on these sites "allows individuals to move freely through multiple communities" and, at the same time, allows a unique sense of community to be developed (McEwan \& Sobre-Denton, 2011, p. 254).

Further, SNS usage potentially can enhance bridging social capital (Jiang \& de Bruijin, 2014; Tian, 2016). Bridging social capital "consists of loose relationships (i.e., weak ties) which serve as bridges connecting a person to a different network, allowing the person to access new perspectives and diffuse information" (Lin, Peng, Kim, Kim, \& LaRose, 2011, p. 422; see also Ribchester, Wakefield, \& Miller, p. 2012). Bridging social capital is acquired through connections with people of diverse backgrounds; that is, the practice of emotional, communicative, and functional competencies as defined in the TC framework. A study investigating Facebook use and adjustments among international students shows that online social networking can increase online bridging capital (Lin et al., 2011, p. 429; see also Choi, Kim, Sung, \& Sohn, 2011; Ellison, Vitak, Gray, \& Lampe, 2014). Another study found that "greater intensity of cross-cultural Facebook interactions was positively associated with a perceived increase in cross-cultural social capital" (Jiang \& de Bruijn, 2014, p. 732).

In short, SNS engagement carries the possibility of enhanced development of multiple TC dimensions among international students. For instance, a study conducted with East Asians studying in the United States indicated that students who use Facebook demonstrate a lower degree of acculturative stress and a higher degree of psychological wellbeing (Park, Song, \& Lee, 2014) - characteristics of emotional competence. Zhu's (2012) study of an online community of Chinese students studying in the 
United States found that online social networking facilitated international students' cultural and ethnic identity development (emotional competence) and helped them develop knowledge and skills for adapting to the cultural space of U.S. university life (creative competence; see also L. Chen \& Hanasono, 2016).

Intercultural friendship has immense potential for enhancing sojourns and advancing international goodwill (French, Bae, Pidada, \& Lee, 2006). Unfortunately, this potential often is not realized - particularly among East Asians (Gareis, 2012; K. Lee \& Ranta, 2014). Many international students desire and expect to develop personal relationships with members of the host community in the United States and to learn about the local culture; however, few actually have U.S. friends, and most relationships among international students and U.S. students are confined to academic contexts (Sakurai, McCall-Worlf, \& Kashinm, 2010). By breaking down communication barriers among the electronically inclined generation (see Mitchell, Gottried, \& Matsa, 2015), SNSs might be a useful tool for enhancing the confidence, knowledge, and skills required for building intercultural relationships (Sakurai et al., 2010). In particular, SNSs potentially can serve as a space to develop TC through virtual intercultural connections when face-to-face interactions with peers of diverse backgrounds are avoided or lacking (Ellison, Steinfield, \& Lampe, 2007; Junco, 2012; Pempek, Yermolayeva, \& Calvert, 2009).

\section{METHODS AND FINDINGS}

The research question addressed by this study is: From the non-native, English-speaking, Japanese college student's perspective, what aspects of transnational-competence development can be facilitated by interactions with people of different cultural backgrounds via a global SNS such as Facebook?

As part of an initial effort to tackle the research question, the author and a colleague conducted a survey with undergraduate Japanese students enrolled at a university in the northwest of the United States. Japanese students are the largest group of international students on this campus. The author, with the help of Japanese student leaders, recruited student participants through email, Facebook, and a Japanese Students Association meeting. Thirty-one volunteers aged $20-24$, about $50 \%$ of the total Japanese student population at the research site, completed the survey. Study participants were undergraduate students from a wide range of majors. The length of their residence in the US ranged from a few months to 5 years. 
The fact that all of the participants were officially enrolled in a universitydegree program based on a TOEFL paper-based test score of at least 525 serves an indicator of their English proficiency. Facebook was the most popular SNS among this group of students.

We designed a survey to investigate perceived effects of intercultural interactions via SNSs on participants' transnational-competence development. The survey involved questions using a 5-point Likert scale ranging from strongly agree to strongly disagree, that addressed all five dimensions of Koehn and Rosenau's (2010) transnational-competence framework (see Table 1). Five questions on the survey dealt with various aspects of analytic competence (see Table 2). Six questions addressed aspects of emotional competence (see Table 3). Four questions involved aspects of creative competence (see Table 4). Six questions addressed aspects of communicative competence (see Table 5). Four questions treated aspects of functional competence (see Table 6). In order to keep the length of the questionnaire reasonable, the survey did not address every single aspect of each competency, but focused on aspects most relevant to SNS usage.

Data collection also involved semi-structured interviews with the 10 (out of the 31) participants who were available for interviewing. A bilingual visiting professor from Japan carried out all of the interviews. The interviews allowed for gaining a deeper understanding of participants' perspectives on the effects of SNS use on transnational-competence development. Interview questions covered four areas: (1) travel and study abroad experiences; (2) SNS usage patterns and habits; (3) thoughts about interactions on SNSs with people who are not Japanese; and (4) thoughts about interactions on SNSs with Japanese people. The interviewer asked the questions in English; the participants responded in both English and Japanese. Some participants switched back and forth between English and Japanese. When study participants tried to explain deeper thoughts or more complicated ideas, they used Japanese. The interviewer later translated responses in Japanese into English. A research assistant transcribed all the interviews. The interviewer also proofread all transcriptions. Working with the interview transcriptions, I used thematic analysis based on grounded theory to discover common themes and shared insights (Strauss \& Corbin, 1994). The interview data proved valuable by revealing variations in SNS use, the nature of relationships built and maintained on SNSs, and users' observations about interactions on SNSs. In addition, the interview data provided information about individual experiences that served to illustrate the 
survey findings. The interview data also highlighted the areas of skill development that stood out according to the participants' perception.

\section{Survey Results}

Table 2 shows the percentages of respondents who indicated agreement or disagreement with statements about SNS use in relation to development of various dimensions of analytic competence. Most participants (90\%) agreed or strongly agreed that use of SNSs allowed for gaining knowledge about local people's values, beliefs, and practices. The majority $(71 \%)$ agreed or strongly agreed that use of SNSs helped increase awareness of ethnic diversity in the host country.

Table 2: Participants' Opinions on SNS Usage in Relation To AnalyticCompetence Development

\begin{tabular}{|c|c|c|c|c|c|}
\hline & SD & $\mathrm{D}$ & $\mathrm{N}$ & $\mathrm{A}$ & SA \\
\hline $\begin{array}{l}\text { Allowed me to gain knowledge } \\
\text { about local people's (i.e., U.S. } \\
\text { Americans') values, beliefs, and } \\
\text { practices. }\end{array}$ & $3 \%$ & $0 \%$ & $7 \%$ & $61 \%$ & $29 \%$ \\
\hline $\begin{array}{l}\text { Increased my understanding of } \\
\text { the local (i.e., } \\
\text { U.S.) political system. }\end{array}$ & $7 \%$ & $29 \%$ & $26 \%$ & $26 \%$ & $13 \%$ \\
\hline $\begin{array}{l}\text { Increased my awareness of the } \\
\text { ethnic diversity in the host } \\
\text { country (i.e., for Japanese } \\
\text { students studying here, the U.S. } \\
\text { is the host country). }\end{array}$ & $0 \%$ & $13 \%$ & $16 \%$ & $58 \%$ & $13 \%$ \\
\hline $\begin{array}{l}\text { Allowed me to know how I am } \\
\text { connected to developments and } \\
\text { events (e.g., economic } \\
\text { development, climate change, } \\
\text { political events, etc.) in other } \\
\text { countries. }\end{array}$ & $7 \%$ & $13 \%$ & $23 \%$ & $32 \%$ & $26 \%$ \\
\hline $\begin{array}{l}\text { Helped me assess how effective } \\
\text { an approach is for working with } \\
\text { people of different backgrounds. }\end{array}$ & $3 \%$ & $3 \%$ & $32 \%$ & $52 \%$ & $10 \%$ \\
\hline
\end{tabular}


More than half (58\% and 62\%, respectively) agreed or strongly agreed that SNSs allowed users (1) to know how they are connected to developments and events in other countries and (2) to assess how effective observed approaches are for working with people of different backgrounds. From the perspective of the participants, therefore, online social networking is helpful for developing four out of five key areas of analytic competence. The one area that fewer than half of the participants (39\%) expressed agreement involved increased understanding of the U.S. political system.

Table 3: Participants' Opinions on SNS Usage in Relation to EmotionalCompetence Development

\begin{tabular}{|c|c|c|c|c|c|}
\hline & SD & $\mathrm{D}$ & $\mathrm{N}$ & A & SA \\
\hline $\begin{array}{l}\text { Motivated me to learn about } \\
\text { different cultural influences. }\end{array}$ & $0 \%$ & $7 \%$ & $13 \%$ & $39 \%$ & $42 \%$ \\
\hline $\begin{array}{l}\text { Increased my interest in } \\
\text { different cultural } \\
\text { experiences. }\end{array}$ & $0 \%$ & $0 \%$ & $13 \%$ & $52 \%$ & $36 \%$ \\
\hline $\begin{array}{l}\text { Helped me enjoy different } \\
\text { people's values, traditions, } \\
\text { experiences, and } \\
\text { perspectives. }\end{array}$ & $0 \%$ & $0 \%$ & $13 \%$ & $52 \%$ & $36 \%$ \\
\hline $\begin{array}{l}\text { Helped me understand why } \\
\text { people of different } \\
\text { backgrounds have unique } \\
\text { values. }\end{array}$ & $0 \%$ & $10 \%$ & $29 \%$ & $48 \%$ & $13 \%$ \\
\hline $\begin{array}{l}\text { Increased my confidence in } \\
\text { dealing with different } \\
\text { people in different cultures. }\end{array}$ & $7 \%$ & $10 \%$ & $32 \%$ & $39 \%$ & $10 \%$ \\
\hline $\begin{array}{l}\text { Helped me feel a sense of } \\
\text { belonging in multiple } \\
\text { cultures. }\end{array}$ & $0 \%$ & $3 \%$ & $16 \%$ & $58 \%$ & $23 \%$ \\
\hline
\end{tabular}

Table 3 shows the percentages of respondents who indicated agreement or disagreement with statements about SNS usage in relation to development of various dimensions of emotional competence. Nearly $90 \%$ of the participants agreed or strongly agreed that online social networking 443 
helped increase interest in different cultural experiences and appreciation for diverse people's values, traditions, experiences, and perspectives. A large majority of the participants $(81 \%)$ believed that use of SNSs motivated them to learn about different cultural influences and helped them feel a sense of belonging in multiple cultures. More than half $(61 \%)$ of the participants agreed or strongly agreed that using SNSs helped them understand why people of different backgrounds have unique values. From the participants' point of view, SNSs helped in developing five out of the six selected dimensions of emotional competence.

\section{Table 4: Participants' Opinions on SNS Usage in Relation to Creative- Competence Development}

\begin{tabular}{lccccc}
\hline & SD & D & N & A & SA \\
\hline $\begin{array}{l}\text { Helped me understand how } \\
\text { people from different } \\
\text { cultures can work together }\end{array}$ & $3 \%$ & $32 \%$ & $32 \%$ & $23 \%$ & $10 \%$ \\
to solve problems. & & & & & \\
$\begin{array}{l}\text { Helped me create new } \\
\text { ways of working with } \\
\text { different people. }\end{array}$ & $3 \%$ & $19 \%$ & $29 \%$ & $32 \%$ & $16 \%$ \\
$\begin{array}{l}\text { Helped me develop the } \\
\text { skill to work with people } \\
\text { who may not always agree } \\
\text { with me. }\end{array}$ & $3 \%$ & $32 \%$ & $32 \%$ & $23 \%$ & $10 \%$ \\
$\begin{array}{l}\text { Helped me find inspiration } \\
\text { from diverse cultural, } \\
\text { societal, and technical } \\
\text { sources. }\end{array}$ & $0 \%$ & $10 \%$ & $16 \%$ & $48 \%$ & $26 \%$ \\
\hline
\end{tabular}

Table 4 shows the percentages of respondents who indicated agreement or disagreement with statements about the use of SNSs in relation to development of various dimensions of creative competence. To gain inspiration from diverse cultural, societal, and technical sources is one area where most participants (74\%) perceived that SNSs had helped. From the participants' point of view, online social networking appeared to be the least helpful for understanding how people from different cultures could work together to solve problems and for developing the skill to work with people 
who might not always agree with you; only $33 \%$ of the participants indicated agreement with these statements.

Table 5: Participants' Opinions on SNS Usage in Relation to Communicative-Competence Development

\begin{tabular}{lccccc}
\hline & SD & D & N & A & SA \\
\hline $\begin{array}{l}\text { Helped me improve my } \\
\text { English. }\end{array}$ & $7 \%$ & $16 \%$ & $7 \%$ & $42 \%$ & $26 \%$ \\
$\begin{array}{l}\text { Improved my nonverbal- } \\
\text { communication skills when } \\
\text { interacting with people from } \\
\text { other cultures. }\end{array}$ & $19 \%$ & $26 \%$ & $16 \%$ & $42 \%$ & $19 \%$ \\
$\begin{array}{l}\text { Improved my ability to } \\
\text { understand messages from }\end{array}$ & $3 \%$ & $3 \%$ & $16 \%$ & $42 \%$ & $19 \%$ \\
$\begin{array}{l}\text { people of different } \\
\text { backgrounds. }\end{array}$ & & & & & \\
$\begin{array}{l}\text { Improved my ability to talk } \\
\text { with people of different } \\
\text { backgrounds. }\end{array}$ & $0 \%$ & $19 \%$ & $13 \%$ & $52 \%$ & $16 \%$ \\
$\begin{array}{l}\text { Helped me feel more } \\
\text { confident in sharing with } \\
\text { others about myself. }\end{array}$ & $7 \%$ & $13 \%$ & $32 \%$ & $36 \%$ & $13 \%$ \\
$\begin{array}{l}\text { Helped me learn to avoid } \\
\text { intercultural } \\
\text { miscommunication }\end{array}$ & $10 \%$ & $19 \%$ & $29 \%$ & $29 \%$ & $13 \%$ \\
\hline
\end{tabular}

Table 5 shows the percentages of respondents who indicated agreement or disagreement with statements about SNS in relation to development of various dimensions of communicative competence. More than half of the participants agreed that online social networking helped improve the following communication skills: English language use, ability to understand messages from people of different backgrounds, and ability to talk with people of different backgrounds. The one area that many participants $(51 \%)$ did not believe SNS had helped was developing nonverbal communication skills for interacting with people from other cultures; this is not surprising as online social networking is devoid of body language, a sense of time and timing, conversation regulators, and the use of silence as shaped by culture. 
Table 6 shows the percentages of respondents who indicated agreement or disagreement with statements about SNS usage in relation to development of various dimensions of functional competence. The only area of functional competence that more than half of the participants $(56 \%)$ believed online social networking had helped involved becoming flexible and willing to meet others' needs when working with different people. The skill area that the fewest participants $(26 \%)$ perceived as a positive outcome of SNSs was improved ability to deal with conflicts involving people from different cultures. Perhaps conflicts on SNSs often are dealt with simply by avoidance or by disconnecting.

All in all, from the participants' perspective, SNS usage is particularly helpful in developing analytic and emotional competence. For most students, it also facilitates the growth of certain aspects of communication competence. It is least helpful in the development of functional competence.

Table 6: Participants' Opinions on SNS Usage in Relation to Functional-Competence Development

\begin{tabular}{|c|c|c|c|c|c|}
\hline & SD & D & $\mathrm{N}$ & A & SA \\
\hline $\begin{array}{l}\text { Helped me build trust with } \\
\text { local people I interact with. }\end{array}$ & $9 \%$ & $3 \%$ & $16 \%$ & $29 \%$ & $16 \%$ \\
\hline $\begin{array}{l}\text { Helped me become more } \\
\text { flexible and willing to meet } \\
\text { others' needs when working } \\
\text { with different people. }\end{array}$ & $3 \%$ & $13 \%$ & $16 \%$ & $29 \%$ & $13 \%$ \\
\hline $\begin{array}{l}\text { Improved my ability to deal } \\
\text { with conflicts or } \\
\text { disagreements with people } \\
\text { from different cultures. }\end{array}$ & $9 \%$ & $3 \%$ & $36 \%$ & $23 \%$ & $3 \%$ \\
\hline $\begin{array}{l}\text { Improved my ability to } \\
\text { complete projects or } \\
\text { accomplish goals when } \\
\text { working with people from } \\
\text { different cultures. }\end{array}$ & $0 \%$ & $13 \%$ & $13 \%$ & $39 \%$ & $13 \%$ \\
\hline
\end{tabular}




\section{Interview Results}

When asked about the preferred SNS for communicating with friends of different cultural backgrounds, all participants indicated Facebook. All but one participant had hundreds of Facebook friends, ranging from 300 to 800 . Most indicated that these Facebook friends were people they had met face to face before. Words that the participants used to describe their Facebook friends included "not strangers," "acquaintances," "real friends," and "close friends."

All but one participant used Facebook every day, ranging from 1-10 hours a day. They all indicated a high level of comfort using Facebook without mentioning any language barrier. When asked about the purposes of Facebook use, the common responses included making foreign friends, staying connected with many friends, viewing updates posted by friends, sharing pictures and videos, and posting diaries. When asked about the communication approach practiced on Facebook, all participants indicated that they used mostly English on Facebook and they used Japanese only when posting something for Japanese friends.

When asked about the potential benefits of using Facebook, the most commonly perceived advantages included ease of contacting people (in particular U.S. Americans), ease of making international friends, and ease of obtaining lots of information (including news) about people near and far. The participants mentioned that SNSs allowed them to "learn about opinions of people of different ages," "learn about different people's ideas," and "see different perspectives shaped by cultures." Some participants shared that they used Facebook to look up information for homework assignments. For instance, one participant indicated that she would "read about different people's opinions and ideas [on Facebook] when writing analytical papers." Another participant mentioned that she would use Facebook to obtain "direct resources from different people for making presentations." For example, she would "learn about the Korean president from Korean friends." In addition, from the participants' point of view, the educational benefits of Facebook included learning and practicing English communication. Some of the participants indicated that, through using Facebook, they had become more comfortable expressing themselves. For instance, one participant shared that she now "writes like Americans do on the Internet."

In a particularly interesting finding, participants distinguished the Japanese communication style used on Facebook from the communication style used by U.S. Americans. The participants perceived that U.S. 
Americans communicated openly about their opinions and feelings on Facebook while Japanese people tended to hide their emotions and avoid expressing opinions on Facebook. For instance, the participants mentioned that "posting only happy, funny things" would be "the Japanese way." For Japanese, moreover, it would "not [be] appropriate to have a long discussion in public place." The participants further stated that they would not post opinions on Facebook. A couple of participants mentioned that "Americans are honest" and "Americans post arguments and opinions" all the time. After using Facebook and other social media sites to interact with U.S. Americans, the participants found themselves being influenced by their U.S. social-media friends' communication style. One of the participants acknowledged that she "became more like Americans [and started to] express agreements and disagreements with both Japanese and American friends."

The main story that emerged from the interview data is that social media is a window to diversity. Exposure to diverse opinions, perspectives, values, and identities expressed freely on SNSs led to perceived growth in all dimensions of transnational competence as indicated by the following survey findings:

- Most interview participants (90\%) agreed or strongly agreed that use of SNSs allowed for gaining knowledge about local people's values, beliefs, and practices. (analytic competence)

- A majority (71\%) agreed or strongly agreed that use of SNSs helped increase awareness of ethnic diversity in the host country. (analytic competence)

- Nearly $90 \%$ of the participants agreed or strongly agreed that online social networking helped increase interest in different cultural experiences and appreciation for diverse people's values, traditions, experiences, and perspectives. (emotional competence)

- A large majority of the participants $(81 \%)$ believed that use of SNSs motivated them to learn about different cultural influences and helped them feel a sense of belonging in multiple cultures. (emotional competence)

- Gaining inspiration from diverse cultural, societal, and technical sources is one creative competence area where most participants (74\%) perceived SNSs had helped. (creative competence)

- More than half of the participants (61\%) agreed that online social 
networking helped improve their ability to understand messages from people of different backgrounds and their ability to talk with people of different backgrounds. (communicative competence)

- More than half of the participants (56\%) believed online social networking had helped them become flexible and willing to meet others' needs when working with different people. (functional competence)

These findings are particularly interesting for Japanese students, as most study participants shared in the interview that direct, open, individualistic communication is not common on SNSs populated by Japanese users. Facebook and other global SNS platforms could be the most accessible sources of diversity for Japanese students, other international students from highly collectivistic and homogenous societies, and those who are not able to connect in person with a variety of people while studying in the United States.

\section{DISCUSSION}

On the basis of study participants' perceptions and reflections, online social networking is helpful for enhancing nearly all aspects of transnational competence, although improvements in certain dimensions stand out more than others. For instance, more participants perceived improvement in analytic, emotional, and communicative competence than in creative and functional competence. Conceivably, these differences in reported outcomes are not just a matter of perception, but also result from various ways and purposes of SNS usage. The majority of the participants used SNSs for staying connected with international friends. The new technology allows users to be in contact with not just a limited circle, but with an open network of hundreds. Moreover, the connections are not merely names in an address book or a stack of business cards; connecting with acquaintances through various types of exchanges can take place every day. Since all the participants interviewed used Facebook every day, the findings of this exploratory study suggest that daily, frequent exposure to diverse intercultural and international interactions via global SNSs contributes to the development of transnational competence.

SNSs are a space designed for voluntary sharing of feelings, opinions, and happenings. When there are hundreds of people of different backgrounds rooted in different places, the sharing promises to be rich in diversity. Hours of daily exposure to such a breadth of diversity is likely to 
contribute to the development of transnational competence that builds upon knowledge of different people's values, beliefs, and practices along with a sense of connectedness to events around the world. The heightened awareness resulting from online social networking is likely to motivate learning about different cultural influences, increase interest in different cultural experiences and appreciation for different values, and allow for finding inspiration from diverse sources. These outcomes do not automatically translate into depth of understanding. For instance, the types of exchanges on SNSs do not necessarily bring about comprehension of the political systems of foreign countries.

Nevertheless, intercultural interactions through online social networking can help to enhance understanding of different ways of working with people of diverse backgrounds. When SNSs are used with attention to distinctive ways of communicating, it appears that users can develop abilities to assess how feasible an approach is for working with people of different backgrounds, to decode and encode messages for effective intercultural communication, and to adjust one's strategies for meeting others' needs in multicultural settings. However, these abilities are mainly in the realm of personal growth rather than skills useful for dealing with long-term, deep interpersonal engagements. For developing the competence required for functions such as building trust and positive relationships, resolving difficult and complicated conflicts, collaborating on complex projects, and accomplishing tasks, exposure on SNSs can only serve to lay a partial foundation (see also Jiang \& de Bruijn, 2014 about Facebook use and gaining of cross-cultural social capital). To develop such skills fully, contextualized face-to-face practices in the real world are likely to be necessary.

A particularly noteworthy part of foundation building that SNSs contribute to is the development of emotional competence. This study indicates that the magnitude of sharing on SNSs serves to facilitate the development of bridging capital and a sense of belonging to multiple cultures. This can translate to intercultural friendship that promises to induce greater empathy with outgroup members as well as reduce anxiety during interactions with people who are of different backgrounds. Despite its virtual reality, intercultural interactions via SNSs potentially help nurture empathy and a sense of transboundary efficacy, which are key elements of emotional competence. Moreover, the nature of sharing on SNSs serves to add to the depth of networking that would not have happened among users otherwise. For instance, intercultural interactions in the form of public forums on Facebook are particularly helpful for users such as the Japanese 
participants who seldom hear diverse personal opinions, direct agreements and disagreements, and open exchanges of perspectives in the public online domain. For such users, the global SNSs are one of the few places where they learn to appreciate differences and find inspiration from diverse perspectives.

In addition, this study indicates that online social networking promises to lay the foundation of intercultural communication skill development. SNSs constitute a nonthreatening, convenient space for speakers of different languages to observe and practice English communication with a diverse audience. For most, daily SNS usage allows for frequent exposure to and, hence, improvement in intercultural communication skills. However, online interactions are limited to verbal and written communication and, therefore, are not particularly helpful for improving nonverbal communication skills. Another limitation is the inadequacy of virtual networking for helping to increase confidence for real-world intercultural interactions. However, findings in this regard are not clear-cut in this study. While interactions on SNSs alone might not help much, the online interactions could enhance or reinforce learning from past and future face-to-face experiences.

\section{RECOMMENDATIONS}

The principal goals of this exploratory study are to (1) break new ground by providing evidence of the type of interesting findings that can be elicited through this kind of research and referenced by other scholars and (2) explore new research pathways that can be refined and expanded in future studies. Given that this study has explored only one group of international students at one institution, further research is required to evaluate the usefulness of online social networking for transnational competence development among international students of different backgrounds. Future studies could involve students of different nationalities studying in the United States and U.S. students studying in different countries.

To investigate further whether the intercultural nature of interactions via SNSs is a key factor contributing to the development of transnational competence, future studies could include comparison with a control group who use SNSs to interact mostly with people from within their own cultural group. For instance, a control group could consist of U.S. native Englishspeaking college students whose Facebook friends are mostly people from their own cultural and linguistic group. Interview questions that would provide insight into the thinking of the participants could include whether international students need mediators to help them navigate through SNSs 
based in the host country. How do international students know what cultural information is reliable? How do they learn to distinguish between cultural nuances in written communication encountered on SNSs?

Furthermore, the language used in the survey and interviews can produce priming effects (see S. X. Chen \& Bond, 2007, and S. W. S. Lee, Oyserman, \& Bond, 2010). Since the survey in this study is in English and the respondents' first language is Japanese, their responses could possibly be shaped by perception of the normative inclination of English speakers (Hong, Morris, Chiu, \& Benet-Martinez, 2000) or by their imagined social norms of the English-speaking culture that they were immersed in (Chen \& Bond, 2010). The use of English could have activated cultural awareness that created psychological distance from Facebook friends of different cultural backgrounds (see S. X. Chen \& Bond, 2007) and thus skewed selfassessment of their transnational competence. The use of English also could have led to an "individual mindset" (S. W. S. Lee et al., 2010, p. 790) that could cause participants to overestimate their improvement in transnational competence. To minimize such potential language-priming effects, future studies should use a bilingual survey in which each question is set forth in both English and the participants' first language. Ideally, moreover, an interview conducted with each participant should follow the participant's completion of the survey. In addition to collecting vital information about SNS usage, individual interviews could serve to explore further participants' evaluation of the helpfulness of online social networking for developing transnational competence. A list of suggested interview questions is included in the appendix to this contribution.

Building on the survey responses, a semi-structured interview can probe deeper into why and how SNS usage facilitates development of different aspects of transnational competence in various degrees as indicated by each participant's survey responses. In other words, instead of using the survey and interviews as two separate sets of data collected at different times, a more rigorous research approach would tightly link the survey (Phase 1) with the interview (Phase 2). Participants would more likely be able to elaborate on their Phase 1 responses during Phase 2 when the interview takes place shortly after completion of the survey. However, two downsides of this research approach are (1) a large-scale online survey would be not feasible and (2) more time is required from study participants. To address the time commitment issue, providing incentives such as gift cards or monetary compensation would be helpful in boosting the participation rate. Lastly, if interviews are conducted in both English and the participants' mother tongue, back translation is recommended. 


\section{CONCLUSION}

Study findings indicate that a global SNS such as Facebook can be a place for learning and developing skills for productive transnational interactions. This exploratory study adds to existing research findings about the educational benefits of social media use by international students. Facebook not only has "powerful effects" on English-language learning among international students (Aydin, 2012, p. 1099); this study indicates that social media usage has the potential of enhancing their communicative competence, a core dimension of transnational competence. Facebook not only offers a useful acculturation tool for international students to learn about host cultures (Mao \& Qian, 2015); this study also suggests that SNS also can contribute to development of the functional dimension of transnational competence that involves working with people of diverse backgrounds. The digital generation not only values the help received from their virtual societies and the wide horizons opened to them on SNSs (Lebedko, 2014); these research findings also suggest that they recognize the educational benefits of accessing diversity via social media. Implicitly, for instance, the Japanese student participants recognized the value of being able to "carry out an uninhibited cultural navigation amid the distinct yet connected zones" encountered on SNSs (Kim, et al., 2009).

The study participants' sharing provides further evidence that bridging social capital can be gained through SNS connections with people of diverse backgrounds (Lin et al., 2011; Ribchester et al., 2012). In addition, the results of this study support the insight that SNSs operate to break down communication barriers (Mitchell et al., 2015) and can be a useful tool for enhancing not only confidence, knowledge, and skills for building intercultural relationships (Sakurai et al., 2010), but also other essential elements of transnational competence as well.

The international students who participated in this study indicated that SNS usage helps in developing analytic competence, emotional competence, and certain aspects of communication competence. On the other hand, they perceived that it is least helpful in the development of functional competence. Is it possible that the encountered variation in educational benefits depends on how users make use of the tool? As Zuckerman (2013) pointed out, information communication technology itself does not guarantee certain outcomes. Online social networking specifically does not automatically bring about all aspects of transnational competence. If international students use SNSs intentionally for sharpening their transnational competence through learning from their peers in the host 
countries and through interactions with friends of diverse linguistic and cultural backgrounds in different parts of the world, social media can be helpful. As educators around the world strive to internationalize instruction and curriculum and to diversify classrooms and campuses in order to prepare the rising generation for the globalized reality of the 21 st century, the promising individual competence-expanding results of this study point to the value of further efforts to investigate how colleges and universities can tap the potential of online social networking as an empowering educational tool.

\section{REFERENCES}

Allport, G. W. (1954). The nature of prejudice. Reading, MA: AddisonWesley.

Amichai-Hamburger, Y., \& McKenna, K. (2006). The contact hypothesis reconsidered: Interacting via the internet. Journal of ComputerMediated Communication, 11, 825-843. doi: 10.1111/j.10836101.2006.00037.x

Alvarez Valencia, J. A., \& Benavides, A. F. (2019). Using social networking sites for language learning to develop intercultural competence in language education programs. Journal of International and Intercultural Communication, 12(1), 23-42. https://doi.org/10.1080/17513057.2018.1503318

Avram, E. M. (2014). Facebook communication in higher education. SEA: Practical Application of Science, 5, 129-134.

Aydin, S. (2012). A review of research on Facebook as an educational environment. Educational Technology Research \& Development, 60, 1093-1106. doi: 10.1007/s11423-012-9260-7

Barker, V., \& Ota, H. (2011). Mixi diary versus Facebook photos: Social networking site use among Japanese and Caucasian American females. Journal of Intercultural Communication Research, 40(1), 39-63. doi: 10.1080/17475759.2011.558321

Blascovich, J., Mendes, W. B., Hunter, S. B., Lickel, B., \& Kowai-Bell, N. (2001). Perceiver threat in social interactions with stigmatized others. Journal of Personality and Social Psychology, 80(2), 253-267.

Chen, L., \& Hanasono, L. K. (2016). The effect of acculturation on Chinese international students' usage of Facebook and Renren. China Media Research, 12(1), 46-60.

Chen, S. X., \& Bond, M. H. (2007). Explaining language priming effects: Further evidence for ethnic affirmation among Chinese-English 
bilinguals. Journal of Language and Social Psychology, 26(4), 398 406.

Chen, S. X., \& Bond, M. H. (2010). Two languages, two personalities? Examining language effects on the expression of personality in a bilingual context. Personality and Social Psychology Bulletin, 36(11), 1514-1528. doi: 10.1177/0146167210385360

Choi, S., Kim, Y., Sung, Y., \& Sohn, D. (2011). Bridging or bonding? A cross-cultural study of social relationships in social networking sites. Information, Communication \& Society, 14, 107-129. doi: 10.1080/13691181003792624

Ellison, N. B., Steinfield, C., \& Lampe, C. (2007). The benefits of Facebook "friends": Social capital and college students' use of online social network sites. Journal of Computer-Mediated Communication, 12, 1143-1168. doi:10.1111/j.1083-6101.2007.00367.x

Ellison, N. B., Vitak, J., Gray, R., \& Lampe, C. (2014). Cultivating social resources on social network sites: Facebook relationship maintenance behaviors and their role in social capital processes. Journal of Computer-Mediated Communication, 19(4), 855-870. doi: $10.1111 / j \mathrm{jcc} 4.12078$

Facebook. (2018). Newsroom: Stats. Retrieved from: https://newsroom.fb.com/company-info/

Fogg, B. J., \& Iizawa, D. (2008). Online persuasion in Facebook and Mixi: A cross-cultural comparison. Persuasive Technology, 5033, 36-46. doi: 10.1007\%2F978-3-540-68504-3_4

French, D. C., Bae, A., Pidada, S., \& Lee, O. (2006). Friendships of Indonesian, South Korean, and U.S. college students. Personal Relationships, 13, 69-81. doi:10.1111/j.1475-6811.2006.00105.x

Gareis, E. (2012). Intercultural friendship: Effects of home and host region. Journal of International and Intercultural Communication, 5(4), 309-328. doi: 10.1080/17513057.2012.691525

Hong, Y. Y., Morris, M. W., Chiu, C. Y., \& Benet-Martínez, V. (2000). Multicultural minds: A dynamic constructivist approach to culture and cognition. American Psychologist, 55, 709-720.

Hung, H., \& Yuen, S. C. (2010). Educational use of social networking technology in higher education. Teaching in Higher Education, 15(6), 703-714. doi: 10.1080/13562517.2010.507307

Hunt, E. (2016). Facebook brings the world three and a bit degrees of separation closer. Retrieved from https://www.theguardian.com/technology/2016/feb/05/facebookbrings-the-world-three-and-a-bit-degrees-of-separation-closer 
Jiang, Y. F., \& de Bruijn, O. (2014). Facebook helps: A case study of crosscultural social networking and social capital. Information, Communication \& Society, 17(6), 732-749. doi:10.1080/1369118X.2013.830636

Jiang, Y. F., de Bruijn, O., \& De Angeli, A. (2009). The perception of cultural differences in online self-presentation. In T. Gross, J. Gulliksen, P. Kotze, L., Oestreicher, P. Palanque, R. Oliveira Prates, \& M. Winckler (Eds.), Human-computer Interaction (pp. 672-685). Berlin, Germany: Springer.

Junco, R. (2012). The relationship between frequency of Facebook use, participation in Facebook activities, and student engagement. Computers \& Education, 58, 162-171. doi: 10.1016/j.compedu.2011.08.004

Khazan, O. (2013, January 4). The entire world is increasingly using Facebook. The Washington Post. Retrieved from http://www.washingtonpost.com/blogs/worldviews/wp/2013/01/04/t he-entire-world-is-increasingly-using-facebook/

Kim, K., Yun, H., \& Yoon, Y. (2009). The Internet as a facilitator of cultural hybridization and interpersonal relationship management for Asian international students in South Korea. Asian Journal of Communication, 19(2), 152-169. doi: 10.1080/01292980902826880

Koehn, P. H., \& Rosenau, J. N. (2010). Transnational competence: Empowering professional curriculums for horizon-rising challenges. Boulder, CO: Paradigm.

Kotowski, M. R., \& Dos Santos, G. M. (2010). The role of the connector in bridging borders through virtual communities. Journal of Borderlands $\quad$ Studies, 25(3-4), 150-158. doi: 10.1080/08865655.2010.9695777

Lebedko, M. G. (2014). Globalization, networking and intercultural communication. Intercultural Communication Studies, XXIII(1) 2841.

Lee, K., \& Ranta, L. (2014). Facebook: facilitating social access and language acquisition for international students? TESL Canada Journal, 31(2), 22-50.

Lee, S. W. S., Oyserman, D., \& Bond, M. H. (2010). Am I doing better than you? That depends on whether you ask me in English or Chinese: Self-enhancement effects of language as a cultural mindset prime. Journal of Experimental Social Psychology, 46(5), 785-791. 
Lin, J., Peng, W., Kim, M., Kim, S. Y., \& LaRose, R. (2011). Social networking and adjustment among international students. New Media \& Society, 14(3), 421-440. doi: 10.1177/1461444811418627

Madge, C., Meek, J., Wellens, J., \& Hooley, T. (2009). Facebook, social integration and informal learning at university: 'It is more for socializing and talking to friends about work than for actually doing work'. Learning, Media, and Technology, 34(2), 141-155. doi: 10.1080/17439880902923606

Mao, Y., \& Qian, Y. (2015). Facebook use and acculturation: The case of overseas Chinese professionals in western countries. International Journal of Communication, 9, 2467-2486.

McEwan, B., \& Guerrero, L. K. (2010). Freshmen engagement through communication: Predicting friendship formation strategies and perceived availability of network resources from communication skills. Communication Studies, 61(4), 445-465. doi:10.1080/10510974.2010.493762

McEwan, B., \& Sobre-Denton, M. (2011). Virtual cosmopolitanism: Constructing third cultures and transmitting social and cultural capital through social media. Journal of International and Intercultural Communication, 4(4), 252-258. doi: 10.1080/17513057.2011.598044

Mitchell, A., Gottried, J., \& Matsa, K. E. (2015). Millennials and political news.

Retrieved from https://www.journalism.org/2015/06/01/millennials-political-news/

Park, N., Song, H., \& Lee, K. M. (2014). Social networking sites and other media use, acculturation stress, and psychological wellbeing among East Asian college students in the united states. Computers in Human Behavior, 36, 138-146. doi: 10.1016/j.chb.2014.03.037

Pempek, T. A., Yermolayeva, Y. A., \& Calvert, S. L. (2009). College students' social networking experiences. Journal of Applied Developmental Psychology, 30(3), 227-238. doi: 10.1016/j.appdev.2008.12.010

Pettigrew, T. F. (2008). Future directions for intergroup contact theory and research. International Journal of Intercultural Relations, 32, 187199. doi: 10.1016/j.ijintrel.2007.12.002

Pew Research Center. (January 9, 2015). Social media update 2014. Retrieved from http://www.pewinternet.org/2015/01/09/socialmedia-update-2014/

Pew Research Center. (June19, 2018). Social media use continues to rise in developing countries but plateaus across developed ones. Retrieved 
from http://www.pewglobal.org/2018/06/19/social-media-usecontinues-to-rise-in-developing-countries-but-plateaus-acrossdeveloped-ones/

Pfister, D. S., \& Soliz, J. (2011). (Re)conceptualizing intercultural communication in a networked society. Journal of International and Intercultural Communication, 4(4), 246-251. doi: 10.1080/17513057.2011.598043

Placencia, M. E., \& Lower, A. (2013). Your kids are so stinkin' cute!:-): Complimenting behavior on Facebook among family and friends. Intercultural Pragmatics, 10(4), 617-646.

Prescott, J., Wilson, S., \& Becket, G. (2013). Facebook use in the learning environment: Do students want this? Learning, Media and Technology, 38(3), 345-350. doi: 10.1080/17439884.2013.788027

Qiu, L., Lin, H., \& Leung, A. K. Y. (2013). Cultural differences and switching of in-group sharing behavior between an American (Facebook) and a Chinese (Renren) social networking site. Journal of Cross-Cultural Psychology, 44(1), 106-121. doi: 10.1177/0022022111434597

Ribchester, C., Wakefield, K., \& Miller, G. (2012). Creating a transitional space for new students through pre-induction social networking. Journal of Geography in Higher Education, 36(3), 455-467. doi: 10.1080/03098265.2011.641172

Sakurai, T., McCall-Worlf, F., \& Kashinm, E. S. (2010). Building intercultural links: The impact of a multicultural intervention programme on social ties of international students in Australia. International Journal of Intercultural Relations, 34, 176-185. doi: 10.1016/j.ijintrel.2009.11.002

Sharma, S. K., Joshi, A., \& Sharma, H. (2016). A multi-analytical approach to predict the Facebook usage in higher education. Computers in Human Behavior, 55, 340-353. doi: 10.1016/j.chb.2015.09.020

Song, Z. (2016). Educating Asian international students: Toward a transcultural paradigm. East Asia, 33(1), 1-8. doi: 10.1007/s12140016-9252-Z

Strauss, A., \& Corbin, J. (1994). Grounded theory methodology an overview. In N. K. Denzin, \& Y.S. Lincoln (Eds.), Handbook of qualitative research (pp. 273-285). Thousand Oaks, CA: Sage.

Tian, X. (2016). Network domains in social networking sites: expectations, meanings, and social capital. Information, Communication \& Society, 19(2), 188-202. doi: 10.1080/1369118X.2015.1050051

The Task Force for Transnational Competence (1997). Towards transnational competence rethinking international education: A U.S- 
Japan case study. (No. 28). New York, NY: Institute of International Education.

Witteborn, S. (2011). Discursive grouping in a virtual forum: Dialogue, difference, and the "intercultural." Journal of International and Intercultural Communication, 4(2), 109-126. doi: 10.1080/17513057.2011.55682

Zhu, Z. (2012). A place we call "home"-International students in virtual context. Journal of International Students, 2(1), 99-106.

Zuckerman, E. (2013). Rewire: Digital cosmopolitans in the age of connection. New York: Norton.

Dr. Phyllis Bo-yuen Ngai teaches in the Department of Communication Studies at The University of Montana-Missoula. Dr. Ngai's research and teaching interests lie at the crossroads of language, culture, communication, and education. Currently, Phyllis teaches courses in intercultural communication, international development communication, and communication for social and behavior change. Email:phyllis.ngai@umontana.edu 